\title{
Intervention at the very early stage of type 2 diabetes
}

\author{
T. Aizawa $\cdot$ Y. Funase
}

Received: 29 September 2010 / Accepted: 8 November 2010 /Published online: 3 December 2010

(C) Springer-Verlag 2010

To the Editor: An Editorial entitled 'Intensified glucose lowering in type 2 diabetes: time for a reappraisal' [1] was published in a recent issue of Diabetologia. We were disappointed that individuals with a very early stage of type 2 diabetes were not considered in this discussion.

Because type 2 diabetes is a chronic disease that starts without any symptoms and can lead to devastating complications and premature death, there are two questions that need to be asked with respect to glucose lowering. One is 'How low should we go?' and the other is 'At what stage of the disease, or when, should it be done?' The authors discussed results from the UK Prospective Diabetes Study, in which newly diagnosed patients had been enrolled, and compared them with the results from more recent studies in which patients with diabetes of long duration had been evaluated [1]. However, little attention is paid to patients with very early stage type 2 diabetes, by which we mean within 1 year or so of the development of diabetes. One can determine the time of diabetes onset exactly if the results of previous blood tests are known. In Japan, and maybe some other countries, this is a realistic expectation: the national health system for the general population is well organised, with approximately $65 \%$ of adults having their plasma glucose and $\mathrm{HbA}_{1 \mathrm{c}}$ measurements assessed annually. Accordingly, patients with type 2 diabetes are often seen by healthcare professionals at the very early stage $[2,3]$.

In the second section, it is stated that 'the scenario changed when drugs were given to people with no symptoms or evidence of vascular disease', where 'drugs'

T. Aizawa $(\bowtie) \cdot$ Y. Funase

Diabetes Center, Aizawa Hospital,

2-5-1, Honjo,

Matsumoto 390-8510, Japan

e-mail: taizawax@ai-hosp.or.jp implies hypoglycaemic agents. This may be an oversimplification. The patients without symptoms or evidence of vascular disease are a highly heterogeneous population in that the majority of the patients with type 2 diabetes for longer than 10 years fall into this category but so do almost all patients with the very early stage of the disease. Should intensified glucose lowering be reappraised in the patients without symptoms or evidence of vascular disease at the very early stage of diabetes? We think the answer is 'no' if the patient is middle-aged or young. Our group have reported the merits of tight glucose control during the very early stage [2, 3], and reversal of impaired glucose tolerance (IGT) to normal glucose tolerance has been observed in a substantial proportion $(20-50 \%)$ of individuals in response to lifestyle modification and/or pharmacological intervention [4-6]. No serious hypoglycaemia occurs in this setting [2-6]. Pancreatic beta cell mass appears undiminished within 1 year of the development of diabetes [7]. Together, these findings strongly indicate that intensified glucose lowering should be the target in patients with very early stage diabetes. Although, by definition, IGT is different from very early stage diabetes, the two are part of the same continuum.

One may say there is no clinical evidence based on a randomised controlled trial showing a benefit of such a practice at this stage of this disease - an argument known as 'clinical trialism' [8]. Diabetic complications never develop in people without diabetes. There is no reason to consider that exposure to glucose levels at the low end of the 'diabetic' range for shorter than 1 year triggers the complications. We think that no well-experienced diabetologist would question the value of intensified glucose lowering during the very early stage of diabetes.

In our opinion, at the very least the Editorial should have included a statement such as 'There are no randomised 
controlled trial-based data for or against intensified glucose lowering in patients with very early stage type 2 diabetes.' Although healthcare professionals may not often see the patients at this stage in some countries, all patients go through it, therefore diabetes care during the first year after development is of paramount importance.

Duality of interest The authors declare that there is no duality of interest associated with this manuscript.

\section{References}

1. Yudkin JS, Richter B, Gale EA (2010) Intensified glucose lowering in type 2 diabetes: time for a reappraisal. Diabetologia 53:20792085

2. Yamada T, Komatsu M, Sato A et al (2001) Treatment of type 2 diabetes: the sooner, the better. J Intern Med 250:255-257
3. Yamada T, Komatsu M, Komiya I et al (2005) Development, progression, and regression of microalbuminuria in Japanese patients with type 2 diabetes under tight glycemic and blood pressure control: the Kashiwa study. Diabetes Care 28:27332738

4. Chiasson JL, Josse RG, Gomis R, STOP-NIDDM Trail Research Group et al (2002) Acarbose for prevention of type 2 diabetes mellitus: the STOP-NIDDM randomised trial. Lancet 359:20722077

5. Eriksson KF, Lindgarde F (1991) Prevention of type 2 (non-insulindependent) diabetes mellitus by diet and physical exercise: the 6-year Malmo feasibility study. Diabetologia 34:891-898

6. Perreault L, Kahn SE, Christophi CA, Knowler WC, Hamman RF, Diabetes Prevention Program Research Group (2009) Regression from pre-diabetes to normal glucose regulation in the diabetes prevention program. Diabetes Care 32:1583-1588

7. Rahier J, Guiot Y, Goebbels RM, Sempoux C, Henquin JC (2008) Pancreatic beta-cell mass in European subjects with type 2 diabetes. Diabetes Obes Metab 10(Suppl 4):32-42

8. Eldor R, Raz I (2009) The individualized target $\mathrm{HbA}_{1 \mathrm{c}}$ : a new method for improving macrovascular risk and glycemia without hypoglycemia and weight gain. Rev Diabet Stud 6:6-12 